Article

\title{
Development and Application of an ICP-AES Method for the Determination of Nutrient and Toxic Elements in Savory Snack Products after Autoclave Dissolution
}

\author{
Natalia Manousi (D) and George A. Zachariadis *(D) \\ Laboratory of Analytical Chemistry, Department of Chemistry, Aristotle University of Thessaloniki, \\ 54124 Thessaloniki, Greece; nmanousi@chem.auth.gr \\ * Correspondence: zacharia@chem.auth.gr \\ Received: 5 November 2020; Accepted: 23 November 2020; Published: 26 November 2020
}

\begin{abstract}
In this study, a method for the determination of trace elements in snacks using inductively coupled plasma-atomic emission spectrometry (ICP-AES) is presented. The examined elements were $\mathrm{Pb}, \mathrm{Ni}, \mathrm{Cr}, \mathrm{Cu}, \mathrm{Mg}, \mathrm{Zn}, \mathrm{Fe}, \mathrm{Al}, \mathrm{Ba}, \mathrm{Ca}, \mathrm{Co}, \mathrm{Mn}$ and $\mathrm{Cd}$. Under the optimized conditions, digestion of $300 \mathrm{mg}$ of the snack samples was performed by the addition of $5 \mathrm{~mL}$ of nitric acid in a Teflon autoclave and by heating the obtained mixture at $120^{\circ} \mathrm{C}$ for $75 \mathrm{~min}$. In order to evaluate the efficiency of the proposed protocol, method linearity, accuracy precision, limits of detection (LODs) and limits of quantification (LOQs) were evaluated. The relative standard deviations (RSD\%) for all elements were lower than $13.5 \%$, demonstrating that the method offered good precision. The relative recoveries values $(\mathrm{R} \%$ ) ranged between $80-120 \%$, demonstrating that the method offered good accuracy. The LODs for all the trace elements ranged between 0.18 and $3.75 \mu \mathrm{g} \mathrm{g}^{-1}$, while the LOQs ranged between 0.60 and $12.50 \mu \mathrm{g} \mathrm{g}^{-1}$. Finally, the proposed protocol was implemented for the analysis of a wide variety of savory snack samples including commercial snacks from corn, potato chips, popcorns, puffed rice cake and crackers.
\end{abstract}

Keywords: metals; snacks; potato chips; popcorn; wet digestion; sample preparation; ICP-AES

\section{Introduction}

Elemental food composition data are important to consumers and health professionals since metals play a significant role in human nutrition, because of their toxic and carcinogenic effects [1]. In foodstuffs, the major chemical elements are sodium, calcium, potassium and magnesium [2]. Other nutrient elements that are considered essential for human health include copper, iron and zinc [3]. Metals such as barium are generally considered non-essential and their function in biological systems is not known [4]. Finally, there are elements like lead, cadmium and mercury that exhibit high toxicity, and they occur in the environment mainly due to environmental pollution from anthropogenic sources [5]. These metals can migrate through the food chain to humans. As a result, it is critical to determine them in foodstuffs.

There are multiple potential sources of mineral occurrence in food samples, including their initial presence in the raw materials, the processing practices used for food production, contamination from the equipment used during production and/or storage and contamination of the environment. Toxic chemical elements primarily enter foodstuffs due to the contact with the environment such as polluted soil, water and air that falls as precipitation with rain and can contaminate food raw materials [6,7].

Snacks like potato chips, corn snacks and popcorns are common in daily diet, while they are widely consumed in large amounts also from children [8]. Potato chips can be produced by deep 
fat frying in order to have a unique texture flavor combination, that makes them desirable for the consumers. Various parameters including nature of oil, temperature and duration of frying, and storage conditions can determine the quality of chips [9]. Popcorn (Zea mays Everta) is another popular snack product being considered healthier than chips due to its higher fiber and antioxidant content [10]. Upon heating to sufficient temperature, the caryopsis expands resulting in a large expansion of volume, producing the desired product [11]. Crackers are also popular snacks with low contents of moisture, sugar and fat that exhibit a thin and crispy texture. Crackers are also widely consumed worldwide [8].

Among the several methods for the determination of trace elements, atomic spectroscopy techniques are considered the most sensitive, selective and rapid. The most widely used spectroscopic techniques for the qualitative and quantitative determination of metals in foodstuffs include inductively coupled plasma atomic emission spectroscopy (ICP-AES) [12], inductively coupled plasma mass spectrometry (ICP-MS) [13] flame atomic absorption spectrometry (FAAS) [14], cold vapor atomic absorption spectroscopy (CV-AAS) [15] and electrothermal atomic absorption spectroscopy (ETAAS) [16]. ICP-AES exhibits many benefits including high sensitivity, fastness, simplicity of analysis and ease in overcoming interferences [12].

For the determination of trace elements in food samples by ICP-AES, the sample has to be converted into a solution. Therefore, sample digestion procedure is necessary prior to sample analysis [17]. Multiple digestion techniques including dry ashing and wet ashing, as well as conventionally heating procedures, microwave digestion and acid bomb digestion have been studied. Wet digestion is an important methodology for the digestion of the trace heavy metals in solid samples. Nitric acid is an important oxidizing acid that can be employed for wet digestion of foodstuffs that have a high carbohydrate and fat content, in order to reduce carbonization and to ensure the efficiency of the digestion process [4].

In this study, a simple and rapid ICP-AES method was developed for the determination of trace elements $(\mathrm{Pb}, \mathrm{Ni}, \mathrm{Cr}, \mathrm{Cu}, \mathrm{Mg}, \mathrm{Zn}, \mathrm{Fe}, \mathrm{Al}, \mathrm{Ba}, \mathrm{Ca}, \mathrm{Co}, \mathrm{Mn}$ and $\mathrm{Cd})$ in savory snack samples (i.e., corn snacks, potato chips, popcorns and crackers) after wet digestion with nitric acid. Various dissolution procedures were investigated in order to achieve complete digestion of the examined samples. Furthermore, validation of the proposed method was performed in terms of linearity, limits of detection, limits of quantification, accuracy and precision. The developed method was successfully employed for the analysis of savory snacks of different types from Greek market.

\section{Materials and Methods}

\subsection{Materials and Chemicals}

Nitric acid $65 \%$ of analytical grade was supplied by Merck (Darmstadt, Germany) and used for sample digestion and solution preparation. High purity double distilled water was used in all the experiments. Stock standard solutions $\left(1000 \mathrm{mg} \mathrm{L}^{-1}\right)$ of lead, nickel, chromium, copper, magnesium, zinc, iron, aluminum, barium, calcium, cobalt, manganese and cadmium in $0.5 \mathrm{M}$ nitric acid were supplied by Merck (Darmstadt, Germany). Working standard solutions were prepared daily by appropriate serial dilutions of the stock solutions in $0.5 \mathrm{M}$ nitric acid.

\subsection{Instrumentation}

In this study, a Perkin-Elmer Optima 3100XL axial viewing ICP-AES equipped with a cyclonic spray chamber and a GemTip cross-flow nebulizer was used for the determination of the trace elements. The samples were introduced into the ICP-AES system at a flow rate of $1.0 \mathrm{~mL} \mathrm{~min}{ }^{-1}$, using a three-channel peristaltic pump and Tygon-type polyvinyl chloride (PVC) peristaltic pump tubes (inner diameter 0.030 in). The nebulizer argon gas flow rate, the auxiliary argon gas flow rate and the plasma argon gas flow rate were $0.85,0.6$ and $15 \mathrm{~L} \mathrm{~min}^{-1}$, respectively. Nine points per peak were used for the measurement of the peak area. The operating conditions of the ICP-AES system were as such: power output: $1.5 \mathrm{~kW}$, pixel resolution: $0.006 \mathrm{~nm}$ at $200 \mathrm{~nm}$, torch type: Fassel type, 
fully demountable and torch alumina injector inner diameter: $2.0 \mathrm{~mm}$. Two analytical wavelengths were recorded for each element and the peak area was chosen as a signal measurement mode. Table 1 summarizes the recorded emission lines for each element.

Table 1. Recorded atomic emission lines for each element.

\begin{tabular}{ccc}
\hline Element & \multicolumn{2}{c}{ Atomic Emission Lines $(\mathbf{n m})$} \\
\hline Barium & 233.527 & 230.425 \\
Cadmium & 226.502 & 214.440 \\
Copper & 324.752 & 224.700 \\
Nickel & 232.003 & 221.648 \\
Lead & 217.000 & 220.353 \\
Zinc & 213.857 & 202.548 \\
Calcium & 317.933 & 396.847 \\
Manganese & 257.610 & 259.372 \\
Magnesium & 279.077 & 280.271 \\
Aluminum & 308.215 & 237.313 \\
Iron & 238.204 & 239.562 \\
Chromium & 283.563 & 357.869 \\
Cobalt & 228.616 & 238.892 \\
\hline
\end{tabular}

Digestion of the snack samples was performed in Teflon ${ }^{\circledR}$ (DuPont, DE, USA) vessels. The vessels were placed in a steel autoclave and heated in a six-position aluminum block (Berghof, BTR, 941, Eningen, Germany). The maximum working volume of the vessels were $50 \mathrm{~mL}$, and the maximum operating temperature was $180{ }^{\circ} \mathrm{C}$.

All digestion vessels, glassware and storage bottles were soaked in $10 \%(v / v)$ nitric acid for at least $24 \mathrm{~h}$ and they were washed extensively with double de-ionized water prior to their use.

\subsection{Sample Collection}

In this work twenty-one snack samples (i.e., nine snacks from corn coded as SFC, three popcorn samples coded as PC, one puffed rice cake sample coded as PRC, six potato chips samples coded as $\mathrm{P}$ and two cracker samples coded as $\mathrm{CR}$ ) were analyzed to determine the concentrations of $\mathrm{Pb}, \mathrm{Ni}, \mathrm{Cr}, \mathrm{Cu}$, $\mathrm{Mg}, \mathrm{Zn}, \mathrm{Fe}, \mathrm{Al}, \mathrm{Ba}, \mathrm{Ca}, \mathrm{Co}, \mathrm{Mn}$ and $\mathrm{Cd}$. The snacks analyzed in this study belong to the most popular brands in Greek market. The following snacks from corn were analyzed: SFC-1 (cheese flavor, oven baked corn snack), SFC-2 (pizza flavor, oven baked corn snack), SFC-3 (cheese flavor, oven baked corn snack), SFC-4 (cheese flavor, oven baked corn snack), SFC-5 (cheese and tomato flavor, oven baked corn snack), SFC-6 (cheese flavor, oven baked corn snack), SFC-7 (oven baked corn snack with peanut and chestnut), SFC-8 (oven baked corn snack with peanut and chestnut) and SFC-9 (bacon flavor, oven baked corn snack). The following popcorn samples from corn were analyzed: PC-1 (popcorn with salt), PC-2 (butter flavor, popcorn sample) and PC-3 (popcorn with salt). The following puffed rice cake sample was analyzed: PRC-1 (oregano flavored puffed rice cakes). The following potato chip samples were analyzed: P-1 (potato chips with salt), P-2 (potato chips with salt), P-3 (potato chips with salt), P-4 (potato chips with oregano flavor), P-5 (potato chips with oregano flavor) and P-6 (potato chips with barbeque flavor). The following cracker samples were analyzed: CR-1 (crackers with salt) and CR-2 (crackers with salt). All samples were purchased from local shops in Thessaloniki, Greece.

\subsection{Validation of the ICP-AES Method}

The herein reported ICP-AES method was validated in terms of linearity, limits of detection (LOD), limits of quantification (LOQ), accuracy and precision.

For the evaluation of method linearity, calibration curves for each element were constructed by plotting the peak area of the optimum emission line to the concentration of the standard solution solutions or spike solutions for standard addition curves. Subsequently, least square linear regression analysis was used to evaluate the slope, intercept and coefficient of determination. 
The method's accuracy was evaluated in terms of bias between nominal and measured concentrations of spiked samples, expressed as relative recovery $(\mathrm{R} \%)$ and the method precision, expressed as relative standard deviation (RSD\%), was evaluated by analyzing in five replicate measurements spiked sample solutions.

Finally, for the LODs and LOQs, ten separate blank solutions were independently prepared and analyzed. The LOD value was the concentration that corresponds to three times the standard deviation of the measurements for the blank solutions divided by the slope of calibration curves for each element, while the LOQ value was the concentration that corresponds to ten times the standard deviation of the measurements for the blank solutions divided by the slope of calibration curves for each element $[18,19]$.

\section{Results and Discussion}

\subsection{Selection of the Emission Line}

The selection of the optimum emission lines was based on the intensity and their sensitivity (i.e., the higher slope among the calibration curves for the recorded emission lines), as well as the absence of spectral interferences. Finally, the following emission lines were chosen Ba $230.425 \mathrm{~nm}$, Cd 226.502 nm, Cu 324.752 nm, Ni 232.003 nm, Pb 217.000 nm; Zn 213.857 nm, Ca 396.847 nm, Mg 280.271 nm, Fe 238.204 nm, Mn 257.610 nm, Al 237.313 nm, Cr 357.869 nm and Co 238.892.

\subsection{Sample Preparation of the Snack Samples}

In order to find the optimal digestion procedure for complete sample decomposition, different wet acid methods were tested. For this purpose, the sample mass was kept constant and different digestion mixtures were evaluated. The final digest was diluted to a final volume of $25 \mathrm{~mL}$ in volumetric flasks with double-deionized water. Table 2 summarizes the observations on the effectiveness of the dissolution tests. Dissolution trials were performed with $300 \mathrm{mg}$ of sample (SFC-1, PC-1, PRC-1, P-1 and CR-1). Further increase of the sample amount resulted in slight sedimentation and it probably required higher consumption of nitric acid. Therefore, $300 \mathrm{mg}$ of sample were chosen to avoid high consumption of sample and chemicals. As it can be observed, in order to obtain a clear sample solution without precipitation, autoclave digestion of $300 \mathrm{mg}$ of sample with $5 \mathrm{~mL}$ of nitric acid for $75 \mathrm{~min}$ at $120^{\circ} \mathrm{C}$ gave the best results. Finally, these conditions were chosen for snack samples digestion. Alternative, digestion time can be further reduced with the use of microwave assisted digestion.

Table 2. Dissolution tests for the digestion of snack samples.

\begin{tabular}{ccccc}
\hline $\begin{array}{c}\text { Sample Mass } \\
(\mathbf{m g})\end{array}$ & Digestion Mixture & Digestion Process & $\begin{array}{c}\text { Digestion } \\
\text { Time (min) }\end{array}$ & Remark \\
\hline 300 & $3 \mathrm{~mL}$ deionized $\mathrm{H}_{2} \mathrm{O}$ & Open vessel, Boiling, $100{ }^{\circ} \mathrm{C}$ & 20 & Not dissolved \\
300 & $5 \mathrm{~mL}$ deionized $\mathrm{H}_{2} \mathrm{O}$ & Open vessel, Boiling, $10{ }^{\circ} \mathrm{C}$ & 20 & Not dissolved \\
300 & $3 \mathrm{~mL}$ conc. $\mathrm{HNO}_{3}$ & Open vessel, Boiling, $120^{\circ} \mathrm{C}$ & 5 & Not dissolved \\
300 & $5 \mathrm{~mL}$ conc. $\mathrm{HNO}_{3}$ & Open vessel, Boiling, $100{ }^{\circ} \mathrm{C}$ & 5 & Not dissolved \\
300 & $3 \mathrm{~mL}$ conc. $\mathrm{HNO}_{3}$ & Autoclave digestion, $80^{\circ} \mathrm{C}$ & 30 & Not dissolved \\
300 & $5 \mathrm{~mL}$ conc. $\mathrm{HNO}_{3}$ & Autoclave digestion, $80^{\circ} \mathrm{C}$ & 30 & Not dissolved \\
300 & $3 \mathrm{~mL}$ conc. $\mathrm{HNO}_{3}$ & Autoclave digestion, $100^{\circ} \mathrm{C}$ & 60 & Not dissolved \\
300 & $5 \mathrm{~mL}$ conc. $\mathrm{HNO}_{3}$ & Autoclave digestion, $100^{\circ} \mathrm{C}$ & 60 & Not dissolved \\
300 & $3 \mathrm{~mL}$ conc. $\mathrm{HNO}_{3}$ & Autoclave digestion, $120^{\circ} \mathrm{C}$ & 75 & Slight sedimentation \\
300 & $5 \mathrm{~mL}$ conc. $\mathrm{HNO}_{3}$ & Autoclave digestion, $120^{\circ} \mathrm{C}$ & 75 & Complete dissolution \\
500 & $5 \mathrm{~mL}$ conc. $\mathrm{HNO}_{3}$ & Autoclave digestion, $120^{\circ} \mathrm{C}$ & 75 & Slight sedimentation \\
\hline
\end{tabular}

\subsection{Figures of Merit}

The performance of the ICP-AES method was evaluated under the conditions described above. Table 3 shows the calibration curve, the linear range and the LOD and LOQ for each element. As it can be seen, coefficients of determination for all metals were very good $\left(r^{2}>0.9998\right)$ and wide 
linear ranges were obtained. According to the specifications of the International Union of Pure and Applied Chemistry (IUPAC) [20], blank solutions were used to calculate the LOD and LOQ values of the method. The LODs and LOQs of the ICP-AES method ranged between $0.18-3.75 \mu \mathrm{g} \mathrm{g}^{-1}$ and $0.60-12.5 \mu \mathrm{g} \mathrm{g}^{-1}$, respectively.

Table 3. Calibration curves, linear range, limits of detection (LODs) and limits of quantification (LOQs) of the developed inductively coupled plasma atomic emission spectroscopy (ICP-AES) method.

\begin{tabular}{ccccccc}
\hline Element & $\begin{array}{c}\text { Emission Line } \\
(\mathbf{n m})\end{array}$ & Slope & $\mathbf{r}^{\mathbf{2}}$ & $\begin{array}{c}\text { LOD } \\
\left(\boldsymbol{\mu} \mathbf{g} \mathbf{g}^{-\mathbf{1}}\right)\end{array}$ & $\begin{array}{c}\text { LOQ } \\
\left(\boldsymbol{\mu} \mathbf{g} \mathbf{g}^{-\mathbf{1}}\right)\end{array}$ & $\begin{array}{c}\text { Upper Limit of Linear Range } \\
\left(\boldsymbol{\mu} \mathbf{g} \mathbf{~ m L} \mathbf{L}^{-\mathbf{1}}\right)\end{array}$ \\
\hline $\mathrm{Ba}$ & 230.425 & 1783.7 & 0.9999 & 0.25 & 0.83 & 4000 \\
$\mathrm{Cd}$ & 226.502 & 1266.6 & 0.9999 & 1.33 & 4.42 & 4000 \\
$\mathrm{Cu}$ & 324.752 & 72655 & 0.9999 & 1.00 & 3.30 & 4000 \\
$\mathrm{Fe}$ & 238.204 & 3042.1 & 0.9999 & 1.18 & 3.94 & 4000 \\
$\mathrm{~Pb}$ & 217.000 & 95.512 & 0.9999 & 3.75 & 12.5 & 4000 \\
$\mathrm{Mn}$ & 257.610 & 31474 & 0.9999 & 0.60 & 2.00 & 4000 \\
$\mathrm{Ni}$ & 232.003 & 532.79 & 0.9999 & 0.25 & 0.83 & 4000 \\
$\mathrm{Zn}$ & 213.857 & 1312.3 & 0.9999 & 1.11 & 3.33 & 4000 \\
$\mathrm{Al}$ & 237 & 589.9 & 0.9998 & 0.24 & 0.82 & 4000 \\
$\mathrm{Cr}$ & 357.869 & 45671 & 0.9998 & 0.18 & 0.60 & 4000 \\
$\mathrm{Co}$ & 238.892 & 1789 & 0.9998 & 1.25 & 4.17 & 4000 \\
$\mathrm{Ca}$ & 396.847 & 2001003 & 0.9999 & 1.25 & 4.17 & 800 \\
$\mathrm{Mg}$ & 280.271 & 58760 & 0.9999 & 0.58 & 1.95 & 800 \\
\hline
\end{tabular}

In order to evaluate the accuracy and the precision of the ICP-AES method, spiked standard solutions at two different concentration levels ( 50 and $100 \mu \mathrm{g} \mathrm{g}^{-1}$ ) were analyzed 5 times. Tables 4 and 5 summarize the accuracy and precision results for the examined elements. The relative recovery in the spiked samples ranged between $80-120 \%$ for all concentration levels, indicating that the accuracy of the ICP-AES method is satisfactory. Finally, the RSD\% values were lower than $13.5 \%$, indicating that the precision of the ICP-AES method is satisfactory.

The herein developed method was compared with other studies reported in the literature. Gopalani et al. [17] performed wet digestions of potato chips and biscuits for the determination of their content in various metals (i.e., aluminum, cadmium, cobalt, chromium, copper, iron, manganese, magnesium, nickel, lead and zinc). For sample dissolution, wet digestion of $1 \mathrm{~g}$ of sample was performed with three different mixtures of acids i.e., $\mathrm{HNO}_{3}: \mathrm{H}_{2} \mathrm{O}_{2}(8: 4), \mathrm{HNO}_{3}: \mathrm{H}_{2} \mathrm{SO}_{4}(8: 4)$ and $\mathrm{HNO}_{3}: \mathrm{HCl}$ (8:4). In total, $12 \mathrm{~mL}$ of reagents were required, while dissolution was achieved at $130{ }^{\circ} \mathrm{C}$ in $3 \mathrm{~h}$. Narin et al. [21] performed wet digestions of potato and corn chips for the determination of iron, zinc, manganese and copper. Dissolution of $1 \mathrm{~g}$ of the sample was achieved by the addition of a mixture of $\mathrm{HNO}_{3}: \mathrm{H}_{2} \mathrm{O}_{2}$ (8:4). In this case, the duration of the wet digestion was also $3 \mathrm{~h}$ at $130{ }^{\circ} \mathrm{C}$, while it required $12 \mathrm{~mL}$ of the dissolution mixture. It can be concluded that the employment of autoclave dissolution can significantly reduce the requirements for sample and reagent consumption, while it also reduce the sample preparation time. It is important to mention that microwave digestion can be employed to further reduce the total analysis time.

\subsection{Analysis of Snack Products}

The results from the analysis of various snack samples collected from the Greek market are presented in Table 6. All samples were analyzed in duplicate. As it can be observed, magnesium and calcium were the major elements in snack samples since their concentrations were between 242.5-1556.3 $\mathrm{g} \mathrm{g} \mathrm{g}^{-1}$ and 31.0-767.4 $\mathrm{gg} \mathrm{g}^{-1}$, respectively. Iron, copper, zinc and aluminum were detected in most samples and their concentrations were between 5.9-305.0 $\mu \mathrm{g} \mathrm{g}^{-1}$ for Fe, 3.3-7.7 $\mu \mathrm{g} \mathrm{g}^{-1}$ for $\mathrm{Cu}, 3.3-19.4 \mu \mathrm{g} \mathrm{g}^{-1}$ for $\mathrm{Zn}$ and 4.6-54.2 $\mu \mathrm{g} \mathrm{g}^{-1}$ for Al. Chromium, nickel, manganese and barium were also present in the snack samples. Their concentrations were between $0.60-1.26 \mu \mathrm{g} \mathrm{g}^{-1} \mathrm{for} \mathrm{Cr}_{\text {, }}$ 0.91-2.1 $\mu \mathrm{g} \mathrm{g}^{-1}$ for $\mathrm{Ni}, 1.9-6.0 \mu \mathrm{g} \mathrm{g}^{-1}$ for $\mathrm{Mn}$ and $0.83-2.30 \mu \mathrm{g} \mathrm{g}^{-1}$ for Ba. Finally, the concentrations for lead, cadmium and cobalt were lower than the method LOD. 
Table 4. Relative recoveries and $\mathrm{RSD} \%$ values for $\mathrm{Ba}, \mathrm{Cd}, \mathrm{Cu}, \mathrm{Fe}, \mathrm{Pb}, \mathrm{Mn}$ and $\mathrm{Ni}$ for the analysis of spiked savory snack samples.

\begin{tabular}{|c|c|c|c|c|c|c|c|c|c|c|c|c|c|c|c|c|c|c|c|c|c|c|}
\hline \multirow[b]{2}{*}{ Sample } & \multirow[b]{2}{*}{$\begin{array}{c}\text { Added } \\
\left(\mu \mathrm{g} \mathrm{g}^{-1}\right)\end{array}$} & \multicolumn{3}{|c|}{$\mathbf{B a}$} & \multicolumn{3}{|c|}{$\mathrm{Cd}$} & \multicolumn{3}{|c|}{$\mathrm{Cu}$} & \multicolumn{3}{|c|}{$\mathrm{Fe}$} & \multicolumn{3}{|c|}{$\mathrm{Pb}$} & \multicolumn{3}{|c|}{ Mn } & \multicolumn{3}{|c|}{$\mathrm{Ni}$} \\
\hline & & \begin{tabular}{|c} 
Found \\
$\left(\mu \mathrm{g} \mathrm{g}^{-1}\right)$
\end{tabular} & $\mathbf{R} \%$ & RSD\% & $\begin{array}{c}\text { Found } \\
\left(\mu \mathrm{g} \mathrm{g}^{-1}\right)\end{array}$ & $\mathbf{R} \%$ & RSD \% & $\begin{array}{c}\text { Found } \\
\left(\mu \mathrm{g} \mathrm{g}^{-1}\right)\end{array}$ & $\mathbf{R} \%$ & SD $\%$ & $\begin{array}{c}\text { Found } \\
\left(\mu \mathrm{g} \mathrm{g}^{-1}\right)\end{array}$ & $\mathbf{R} \%$ & RSD $\%$ & $\begin{array}{c}\text { Found } \\
\left(\mu \mathrm{g} \mathrm{g}^{-1}\right)\end{array}$ & $\mathbf{R} \%$ & SD\% & $\begin{array}{c}\text { Found } \\
\left(\mu \mathrm{g} \mathrm{g}^{-1}\right)\end{array}$ & $\mathbf{R} \%$ & RSD\% & $\begin{array}{c}\text { Found } \\
\left(\mathrm{\mu g} \mathrm{g} \mathrm{g}^{-1}\right)\end{array}$ & $\mathbf{R} \%$ & RSD $\%$ \\
\hline \multirow{3}{*}{ SFC-3 } & 0 & $1.1 \pm 0.1$ & & 9.1 & $<$ LOD & & & $3.7 \pm 0.1$ & & 2. & $12.2 \pm 0.5$ & & 4. & $<\mathrm{LOD}$ & & & $<$ LOD & & & $<\mathrm{LOD}$ & & \\
\hline & 50 & & & & & & & & & & & & & & & & & & & & .0 & .0 \\
\hline & 100 & $103.7 \pm 14.0$ & 102.6 & 13.5 & $102.1 \pm 12$ & 102.1 & 11 & $7.7 \pm 12$ & 114.0 & 10.2 & $123.0 \pm 1.0$ & 110.8 & 0.8 & $93.0 \pm 4.0$ & 93.0 & 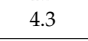 & $99.0 \pm 12.0$ & 99.0 & 12.3 & $116.2 \pm 10$ & 116.2 & 8.6 \\
\hline \multirow{3}{*}{ PC-3 } & 0 & $3+0$ & & 6.1 & $<\mathrm{LOD}$ & & & $3+03$ & & 7.0 & $1+13$ & & 76 & $<\mathrm{LOD}$ & & & $21+02$ & & 9 & & & \\
\hline & 50 & \pm & 94.5 & 12 & $47.0 \pm 4.3$ & 101.4 & 9.1 & $8 \pm$ & 9 & 8. & .0 & 113. & 6 & 52.5 & 105. & 1.1 & & 109.7 & 5. & 49.1 & 98.2 & 2.6 \\
\hline & 100 & $100.3 \pm 3$ & 98.0 & 3 & $99.0 \pm 3.0$ & 99.0 & 3.6 & $119.6 \pm 7.1$ & 115.3 & 5.9 & $135.0 \pm 4.0$ & 117.9 & 3.0 & $117.0 \pm 3.0$ & 117.0 & 2.6 & $98.3 \pm 9.0$ & 96. & 9.2 & $115.0 \pm 4.0$ & 115.0 & 3.5 \\
\hline \multirow{3}{*}{ P-1 } & 0 & $1.3 \pm 0.1$ & & 7.7 & $<\mathrm{LOD}$ & & & $\mathrm{D}^{1}$ & & & $25.4 \pm 1.5$ & & 5.9 & $<\mathrm{LOD}$ & & & $2.3 \pm 0.1$ & & 4.3 & $<$ LOD & & \\
\hline & 5 & & 87 & 1.6 & & 102 & 0 & & & & & 93 & & & & & & & 0.2 & & & 1.4 \\
\hline & 100 & $98.0 \pm 1.1$ & 96.7 & 1.1 & $97.0 \pm 2.0$ & 97.0 & 2.1 & $107.0 \pm 2.0$ & 107.0 & 1.9 & $138.4 \pm 2.0$ & 113.0 & 1.4 & $108.6 \pm 9.0$ & 108.6 & 8.3 & $100.3 \pm 1.0$ & 98.0 & 1.0 & $100.0 \pm 3.0$ & 100.0 & 3.0 \\
\hline \multirow[t]{2}{*}{ CR-1 } & 50 & & & 2.1 & \pm 0 & 102.6 & 1. & & 10 & 9.3 & & 91 & 0 & $48.1 \pm$ & & & & 98 & 9.4 & $=0.1$ & 92 & 0.2 \\
\hline & 100 & $83.0 \pm 4.0$ & 83.0 & 4.8 & $84.0 \pm 2.1$ & 84.1 & 2.5 & $101.0 \pm 2.0$ & 101.0 & 2.0 & $119.1 \pm 2.0$ & 102.0 & 1.7 & $80.0 \pm 4.0$ & 80.0 & 5.1 & $89.1 \pm 3.0$ & 89.1 & 3.4 & $99.1 \pm 3.0$ & 99.1 & 3.0 \\
\hline
\end{tabular}

Table 5. Relative recoveries and $\mathrm{RSD} \%$ values for $\mathrm{Zn}, \mathrm{Al}, \mathrm{Cr}, \mathrm{Co}, \mathrm{Ca}$ and $\mathrm{Mg}$ for the analysis of spiked savory snack samples.

\begin{tabular}{|c|c|c|c|c|c|c|c|c|c|c|c|c|c|c|c|c|c|c|c|}
\hline \multirow[b]{2}{*}{ Sample } & \multirow[b]{2}{*}{$\begin{array}{c}\text { Added } \\
\left(\mu \mathrm{g} \mathrm{g}^{-1}\right)\end{array}$} & \multicolumn{3}{|c|}{$\mathrm{Zn}$} & \multicolumn{3}{|c|}{$\mathrm{Al}$} & \multicolumn{3}{|c|}{$\mathrm{Cr}$} & \multicolumn{3}{|c|}{ Co } & \multicolumn{3}{|c|}{$\mathrm{Ca}$} & \multicolumn{3}{|c|}{$\mathrm{Mg}$} \\
\hline & & $\begin{array}{c}\text { Found } \\
\left(\mu \mathrm{g} \mathrm{g}^{-1}\right)\end{array}$ & $\mathbf{R} \%$ & RSD $\%$ & $\begin{array}{c}\text { Found } \\
\left(\mu \mathrm{g} \mathrm{g}^{-1}\right)\end{array}$ & $\mathbf{R} \%$ & RSD $\%$ & $\begin{array}{c}\text { Found } \\
\left(\mu^{-1} g^{-1}\right)\end{array}$ & $\mathbf{R} \%$ & RSD $\%$ & $\begin{array}{c}\text { Found } \\
\left(\mu \mathrm{g} \mathrm{g}^{-1}\right)\end{array}$ & $\mathbf{R} \%$ & RSD $\%$ & $\begin{array}{c}\text { Found } \\
\left(\mu \mathrm{g} \mathrm{g}^{-1}\right)\end{array}$ & $\mathbf{R} \%$ & RSD $\%$ & $\begin{array}{c}\text { Found } \\
\left(\mu \mathrm{g} \mathrm{g}^{-1}\right)\end{array}$ & $\mathbf{R} \%$ & RSD \% \\
\hline \multirow{3}{*}{ SFC-3 } & 0 & $9.1 \pm 0.9$ & 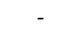 & 9.9 & $11.2 \pm 1.1$ & - & 9.8 & $<\mathrm{LOD}$ & - & - & $<\mathrm{LOD}$ & - & - & $754.1 \pm 3.7$ & - & 0.5 & $351.9 \pm 20.4$ & - & 5.8 \\
\hline & 50 & $65.4 \pm$ & 112.6 & 0 & & 99.3 & 1.5 & $49.6 \pm 0.1$ & 99.3 & 0.2 & $53.9 \pm 7.1$ & 107.8 & 13.2 & & 93.6 & 2.5 & & 118.1 & 5.4 \\
\hline & 100 & $124.1 \pm 13.0$ & 115.0 & 10.5 & $115.0 \pm 2.0$ & 103.8 & 1.7 & $109.3 \pm 1.1$ & 109.3 & 1.0 & $106.0 \pm 14.0$ & 106.0 & 13.2 & $847.1 \pm 30$ & 93.0 & 3.5 & $438.9 \pm 20$ & 87.0 & 4.6 \\
\hline \multirow{3}{*}{ PC-3 } & 0 & $12.8 \pm 1.3$ & & 10.2 & $<\mathrm{LOD}$ & - & - & $\mathrm{D}^{1}$ & - & - & $<$ LOD & - & - & $53.0 \pm 4.3$ & - & 3.5 & $645.0 \pm 63.6$ & - & 9.9 \\
\hline & 50 & $55.6 \pm 4.6$ & 85.7 & 8.3 & $55.6 \pm 5.1$ & 99.4 & 9.2 & $49.7 \pm 1.1$ & 99.4 & 2.2 & $55.7 \pm 2.5$ & 111.4 & 4.5 & $97.3 \pm 5.0$ & 88.6 & 5.2 & $699.7 \pm 65.0$ & 109.5 & 9.3 \\
\hline & 100 & $131.7 \pm 1.9$ & 118.9 & 1.4 & $105.0 \pm 5.0$ & 105.0 & 4.7 & $119.3 \pm 1.1$ & 119.3 & 0.9 & $98.3 \pm 4.2$ & 98.3 & 4.3 & $137.3 \pm 5$ & 84.0 & 3.6 & $762.1 \pm 50.3$ & 117.0 & 6.6 \\
\hline \multirow{3}{*}{ P-1 } & 0 & $9.7 \pm 0.6$ & - & 6.2 & $8.6 \pm 0.5$ & - & 5.8 & $1.3 \pm 0.1$ & - & 7.7 & $<\mathrm{LOD}$ & - & - & $115.1 \pm 6.9$ & - & 6.0 & $1295.3 \pm 85.6$ & - & 6.6 \\
\hline & 50 & $55.2 \pm 1.1$ & 90.9 & 2.0 & $49.6 \pm 1.4$ & 0 & 2.8 & $50.9 \pm 0.3$ & 99.1 & 0.6 & $44.4 \pm 0.4$ & 88.5 & مو & 160.8 & 91.3 & 3.1 & $1345.8 \pm 90.0$ & 100.9 & 6.7 \\
\hline & 100 & $115.7 \pm 2.0$ & 106.0 & 1.7 & $109.5 \pm 4.3$ & 100.9 & 3.9 & $107.3 \pm 2.0$ & 106.0 & 1.9 & $96.2 \pm 4.3$ & 96.2 & 4.7 & $205.1 \pm 18$ & 90.0 & 8.8 & $1404.4 \pm 12.4$ & 109.0 & 0.9 \\
\hline \multirow[t]{2}{*}{ CR-1 } & 50 & $43.8 \pm 2.1$ & 87.5 & 4.8 & $79.2 \pm 3.5$ & 98 & 4.4 & $50.1 \pm 0.5$ & 98 & 1.0 & $50.7 \pm 3.1$ & 101 & 6.1 & $1 \pm 50$ & 86.9 & 13.3 & $1268.1+75.0$ & 102.7 & 5.9 \\
\hline & 100 & $99.1 \pm 10.0$ & 85.7 & 10.0 & $126.2 \pm 3.0$ & 102.0 & 2.4 & $103.0 \pm 4.0$ & 102.0 & 3.9 & $87.5 \pm 3.2$ & 87.5 & 3.7 & $419.6 \pm 30$ & 87.0 & 7.1 & $1300.0 \pm 13.1$ & 83.0 & 1.0 \\
\hline
\end{tabular}

${ }^{1}$ D: Detected. 
Table 6. Metal concentrations in commercial snack samples.

\begin{tabular}{|c|c|c|c|c|c|c|c|c|c|c|c|c|c|}
\hline Sample & $\begin{array}{c}\text { Ba } \\
\left(\mu \mathrm{g} \mathrm{g}^{-1}\right)\end{array}$ & $\begin{array}{c}\mathrm{Cd} \\
\left(\mu \mathrm{g} \mathrm{g}^{-1}\right)\end{array}$ & $\begin{array}{c}\mathrm{Cu} \\
\left(\mu \mathrm{g} \mathrm{g}^{-1}\right)\end{array}$ & $\begin{array}{c}F e \\
\left(\mu \mathrm{g} \mathrm{g}^{-1}\right)\end{array}$ & $\begin{array}{c}\mathrm{Pb} \\
\left(\mu \mathrm{g} \mathrm{g}^{-1}\right)\end{array}$ & $\begin{array}{c}M n \\
\left(\mu g^{-1}\right)\end{array}$ & $\begin{array}{c}\mathrm{Ni} \\
\left(\mu \mathrm{g} \mathrm{g}^{-1}\right)\end{array}$ & $\begin{array}{c}\mathrm{Zn} \\
\left(\mu \mathrm{g} \mathrm{g}^{-1}\right)\end{array}$ & $\begin{array}{c}\mathrm{Cr} \\
\left(\mu \mathrm{g} \mathrm{g}^{-1}\right)\end{array}$ & $\begin{array}{c}\text { Co } \\
\left(\mu \mathrm{g} \mathrm{g}^{-1}\right)\end{array}$ & $\begin{array}{c}\mathrm{Ca} \\
\left(\mu \mathrm{g} \mathrm{g}^{-1}\right)\end{array}$ & $\begin{array}{c}\mathrm{Mg} \\
\left(\mu \mathrm{g} \mathrm{g}^{-1}\right)\end{array}$ & $\begin{array}{c}\mathrm{Al} \\
\left(\mu \mathrm{g} \mathrm{g}^{-1}\right)\end{array}$ \\
\hline SFC-1 & $0.83 \pm 0.01$ & $<\mathrm{LOD}$ & $7.7 \pm 0.1$ & $24.0 \pm 2.3$ & $<\mathrm{LOD}$ & $<\mathrm{LOD}$ & $<\mathrm{LOD}$ & $14.1 \pm 0.7$ & $1.1 \pm 0.1$ & $<\mathrm{LOD}$ & $767.4 \pm 4.7$ & $521.1 \pm 29.6$ & $8.2 \pm 0.4$ \\
\hline SFC-2 & $<\mathrm{LOD}$ & $<\mathrm{LOD}$ & $5.8 \pm 0.3$ & $305.0 \pm 7.7$ & $<\mathrm{LOD}$ & $<\mathrm{LOD}$ & $2.10 \pm 0.1$ & $5.9 \pm 0.1$ & $\mathrm{D}$ & $<\mathrm{LOD}$ & $453.0 \pm 2.1$ & $317.8 \pm 14.5$ & $54.2 \pm 3.3$ \\
\hline SFC-3 & $1.07 \pm 0.09$ & $<\mathrm{LOD}$ & $3.7 \pm 0.1$ & $12.2 \pm 0.5$ & $<\mathrm{LOD}$ & $<\mathrm{LOD}$ & $<\mathrm{LOD}$ & $9.1 \pm 0.9$ & D & $<\mathrm{LOD}$ & $754.1 \pm 3.7$ & $351.9 \pm 20.4$ & $11.2 \pm 1.1$ \\
\hline SFC-4 & $<\mathrm{LOD}$ & $<\mathrm{LOD}$ & $3.7 \pm 0.2$ & $13.9 \pm 0.4$ & $<\mathrm{LOD}$ & $<\mathrm{LOD}$ & $<\mathrm{LOD}$ & $8.2 \pm 0.5$ & $\mathrm{D}$ & $<\mathrm{LOD}$ & $321.7 \pm 17.9$ & $465.7 \pm 17.7$ & $5.6 \pm 0.9$ \\
\hline SFC-5 & $<\mathrm{LOD}$ & $<\mathrm{LOD}$ & $\mathrm{D}^{1}$ & $6.8 \pm 0.1$ & $<\mathrm{LOD}$ & $<\mathrm{LOD}$ & $<\mathrm{LOD}$ & $8.1 \pm 0.5$ & D & $<\mathrm{LOD}$ & $550.3 \pm 37.9$ & $502.6 \pm 18.2$ & $<\mathrm{LOD}$ \\
\hline SFC-6 & $<$ LOD & $<$ LOD & $\mathrm{D}$ & $5.9 \pm 0.1$ & $<\mathrm{LOD}$ & $<\mathrm{LOD}$ & $\mathrm{D}$ & $\mathrm{D}$ & $\mathrm{D}$ & $<$ LOD & $184.9 \pm 7.2$ & $242.5 \pm 22.0$ & $<\mathrm{LOD}$ \\
\hline SFC-7 & $<\mathrm{LOD}$ & $<$ LOD & $5.8 \pm 0.3$ & $9.5 \pm 0.7$ & $<\mathrm{LOD}$ & $6.0 \pm 0,1$ & $<\mathrm{LOD}$ & $15.9 \pm 0.2$ & $\mathrm{D}$ & $<$ LOD & $212.9 \pm 18.3$ & $1060.0 \pm 84.9$ & $<\mathrm{LOD}$ \\
\hline SFC-8 & $2.15 \pm 0.07$ & $<\mathrm{LOD}$ & $4.8 \pm 0.3$ & $9.9 \pm 0.2$ & $<\mathrm{LOD}$ & $3.8 \pm 0.2$ & $<\mathrm{LOD}$ & $13.3 \pm 1.1$ & $<\mathrm{LOD}$ & $<\mathrm{LOD}$ & $161.0 \pm 1.4$ & $872.9 \pm 38.4$ & $9.6 \pm 0.8$ \\
\hline SFC-9 & $0.85 \pm 0.07$ & $<$ LOD & $\mathrm{D}$ & $11.1 \pm 0.2$ & $<\mathrm{LOD}$ & $<\mathrm{LOD}$ & $<$ LOD & $4.8 \pm 0.4$ & $<$ LOD & $<\mathrm{LOD}$ & $185.4 \pm 6.5$ & $604.3 \pm 3.6$ & $12.4 \pm 0.2$ \\
\hline PC-1 & $<$ LOD & $<\mathrm{LOD}$ & D & $15.2 \pm 0.2$ & $<\mathrm{LOD}$ & $<\mathrm{LOD}$ & $<\mathrm{LOD}$ & $12.6 \pm 0.1$ & $\mathrm{D}$ & $<\mathrm{LOD}$ & $170.8 \pm 1.1$ & $927.9 \pm 40.4$ & $<\mathrm{LOD}$ \\
\hline PC-2 & $2.05 \pm 0.07$ & $<$ LOD & D & $20.5 \pm 1.2$ & $<\mathrm{LOD}$ & $1.9 \pm 0.1$ & $<\mathrm{LOD}$ & $19.4 \pm 0.1$ & $0.62 \pm 0.06$ & $<$ LOD & $71.9 \pm 2.7$ & $1225.0 \pm 35.4$ & $4.6 \pm 0.1$ \\
\hline PC-3 & $2.30 \pm 0.14$ & $<\mathrm{LOD}$ & $4.3 \pm 0.3$ & $17.1 \pm 1.3$ & $<\mathrm{LOD}$ & $2.1 \pm 0.2$ & $<\mathrm{LOD}$ & $12.8 \pm 1.3$ & $\mathrm{D}$ & $<\mathrm{LOD}$ & $53.0 \pm 4.3$ & $645.0 \pm 63.6$ & $<\mathrm{LOD}$ \\
\hline P-1 & $1.32 \pm 0.11$ & $<\mathrm{LOD}$ & $\mathrm{D}$ & $25.4 \pm 1.5$ & $<\mathrm{LOD}$ & $2.3 \pm 0.1$ & $<\mathrm{LOD}$ & $9.7 \pm 0.6$ & $1.26 \pm 0.1$ & $<\mathrm{LOD}$ & $115.1 \pm 6.9$ & $1295.3 \pm 85.6$ & $8.6 \pm 0.5$ \\
\hline P-2 & $0.83 \pm 0.02$ & $<\mathrm{LOD}$ & $3.3 \pm 0.2$ & $16.3 \pm 0.6$ & $<\mathrm{LOD}$ & $\mathrm{D}$ & $<\mathrm{LOD}$ & $9.1 \pm 0.4$ & $0.60 \pm 0.06$ & $<\mathrm{LOD}$ & $201.3 \pm 1.8$ & $666.6 \pm 37.6$ & $11.3 \pm 0.2$ \\
\hline P-3 & $<\mathrm{LOD}$ & $<\mathrm{LOD}$ & $<$ LOD & $11.7 \pm 0.1$ & $<\mathrm{LOD}$ & $<\mathrm{LOD}$ & $0.91 \pm 0.01$ & $4.0 \pm 0.1$ & $\mathrm{D}$ & $<\mathrm{LOD}$ & $31.0 \pm 4.2$ & $230.0 \pm 14.1$ & $16.3 \pm 1.5$ \\
\hline P-4 & $<\mathrm{LOD}$ & $<\mathrm{LOD}$ & $\mathrm{D}$ & $11.3 \pm 0.6$ & $<\mathrm{LOD}$ & $<\mathrm{LOD}$ & $<\mathrm{LOD}$ & $6.2 \pm 0.6$ & D & $<\mathrm{LOD}$ & $216.2 \pm 14.7$ & $759.1 \pm 51.5$ & $9.8 \pm 0.3$ \\
\hline P-5 & $<$ LOD & $<$ LOD & $<\mathrm{LOD}$ & $13.7 \pm 1.3$ & $<$ LOD & $<$ LOD & $<\mathrm{LOD}$ & $\mathrm{D}$ & $\mathrm{D}$ & $<\mathrm{LOD}$ & $298.3 \pm 2.3$ & $767.7 \pm 14.7$ & $6.2 \pm 0.1$ \\
\hline P-6 & $<\mathrm{LOD}$ & $<\mathrm{LOD}$ & $\mathrm{D}$ & $11.2 \pm 0.4$ & $<\mathrm{LOD}$ & $<\mathrm{LOD}$ & $\mathrm{D}$ & $3.4 \pm 0.2$ & $<\mathrm{LOD}$ & $<\mathrm{LOD}$ & $360.1 \pm 5.3$ & $690.0 \pm 14.1$ & $\mathrm{D}$ \\
\hline PRC-1 & $<\mathrm{LOD}$ & $<\mathrm{LOD}$ & $<\mathrm{LOD}$ & $12.6 \pm 1.2$ & $<\mathrm{LOD}$ & $<\mathrm{LOD}$ & $1.8 \pm 0.1$ & $6.5 \pm 0.2$ & $<\mathrm{LOD}$ & $<\mathrm{LOD}$ & $153.1 \pm 4.9$ & $1556.3 \pm 56.9$ & $7.2 \pm 0.3$ \\
\hline CR-1 & $<$ LOD & $<$ LOD & D & $17.1 \pm 1.6$ & $<\mathrm{LOD}$ & $\mathrm{D}$ & $\mathrm{D}$ & $13.4 \pm 0.7$ & $0.95 \pm 0.03$ & $<$ LOD & $332.6 \pm 4.3$ & $1216.7 \pm 75.2$ & $24.2 \pm 0.1$ \\
\hline CR-2 & $1.25 \pm 0.07$ & $<\mathrm{LOD}$ & $<\mathrm{LOD}$ & $12.0 \pm 0.3$ & $<\mathrm{LOD}$ & $\mathrm{D}$ & $2.1 \pm 0.1$ & $3.3 \pm 0.1$ & $1.11 \pm 0.02$ & $<\mathrm{LOD}$ & $272.1 \pm 24.8$ & $255.5 \pm 6.2$ & $8.1 \pm 0.3$ \\
\hline
\end{tabular}

${ }^{1}$ D: Detected. 


\section{Conclusions}

In this work, a simple and rapid ICP-AES method was developed and applied for the determination of major, minor and trace elements ( $\mathrm{Pb}, \mathrm{Ni}, \mathrm{Cr}, \mathrm{Cu}, \mathrm{Mg}, \mathrm{Zn}, \mathrm{Fe}, \mathrm{Al}, \mathrm{Ba}, \mathrm{Ca}, \mathrm{Co}, \mathrm{Mn}$ and $\mathrm{Cd}$ ) in snack samples. Various wet digestion procedures with nitric acid were evaluated for the complete dissolution of the snack samples. It was observed that $5 \mathrm{~mL}$ of nitric acid was required for the digestion of $300 \mathrm{mg}$ of snack samples at $120^{\circ} \mathrm{C}$, in a steel autoclave with Teflon vessels. After, optimization of the digestion procedure of the snack samples, the proposed method was validated in terms of linearity, LOD and LOQ values, accuracy and precision. Finally, twenty-one snack samples (i.e., potato chips, snacks from corn, popcorns, puffed rice cake and crackers) from the local market were analyzed. Calcium and magnesium were the major elements in the samples. Nickel, chromium, coper, manganese, zinc, iron, aluminum and barium were also quantitatively determined in most samples. Finally, lead, cadmium and cobalt were not detected in the samples. The proposed method is likely to be applicable to the analysis of other similar complex food products.

Author Contributions: Conceptualization, G.A.Z.; methodology, N.M., G.A.Z.; Experimental work, N.M.; writing—original draft preparation, N.M.; writing—review and editing, G.A.Z.; supervision, G.A.Z. All authors have read and agreed to the published version of the manuscript.

Funding: This research received no external funding.

Conflicts of Interest: The authors declare no conflict of interest.

\section{References}

1. Das Graças Korn, M.; Da Boa Morte, E.S.; dos Santos, D.C.M.B.; Castro, J.T.; Barbosa, J.T.P.; Teixeira, A.P.; Fernandes, A.P.; Welz, B.; dos Santos, W.P.C.; dos Santos, E.B.G.N.; et al. Sample Preparation for the Determination of Metals in Food Samples Using Spectroanalytical Methods-A Review. Appl. Spectrosc. Rev. 2008, 43, 67-92. [CrossRef]

2. Akpinar-Bayizit, A.; Turan, M.A.; Yilmaz-Ersan, L.; Taban, N. Inductively coupled plasma optical-emission spectroscopy determination of major and minor elements in vinegar. Not. Bot. Horti Agrobot. Cluj-Napoca 2010, 38, 64-68.

3. Momen, A.A.; Zachariadis, G.A.; Anthemidis, A.N.; Stratis, J.A. Investigation of four digestion procedures for multi-element determination of toxic and nutrient elements in legumes by inductively coupled plasma-optical emission spectrometry. Anal. Chim. Acta 2006, 565, 81-88. [CrossRef]

4. Momen, A.A.; Zachariadis, G.A.; Anthemidis, A.N.; Stratis, J.A. Use of fractional factorial design for optimization of digestion procedures followed by multi-element determination of essential and non-essential elements in nuts using ICP-OES technique. Talanta 2006, 71, 443-451. [CrossRef]

5. Zachariadis, G.A.; Anthemidis, A.N.; Caniou, I.; Stratis, J.A. Determination of Lead, Cadmium and Mercury in Surface Marine Sediments and Mussels. Int. J. Environ. Anal. Chem. 2001, 80, 153-166. [CrossRef]

6. Morgan, J.N. Effects of processing on heavy metal content of foods. In Advances in Experimental Medicine and Biology; Springer: Boston, MA, USA, 1999; pp. 195-211.

7. Hajeb, P.; Sloth, J.J.; Shakibazadeh, S.; Mahyudin, N.A.; Afsah-Hejri, L. Toxic Elements in Food: Occurrence, Binding, and Reduction Approaches. Compr. Rev. Food Sci. Food Saf. 2014, 13, 457-472. [CrossRef]

8. Venkatachalam, K.; Nagarajan, M. Physicochemical and sensory properties of savory crackers incorporating green gram flour to partially or wholly replace wheat flour. Ital. J. Food Sci. 2017, 29, 2017-2599.

9. Kaur, A.; Singh, N.; Ezekiel, R. Quality Parameters of Potato Chips from Different Potato Cultivars: Effect of Prior Storage and Frying Temperatures. Int. J. Food Prop. 2008, 11, 791-803. [CrossRef]

10. Coco, M.G.; Vinson, J.A. Analysis of Popcorn (Zea Mays L. var. Everta) for Antioxidant Capacity and Total Phenolic Content. Antioxidants 2019, 8, 22. [CrossRef] [PubMed]

11. Sweley, J.C.; Rose, D.J.; Jackson, D.S. Quality Traits and Popping Performance Considerations for Popcorn (Zea mays Everta). Food Rev. Int. 2013, 29, 157-177. [CrossRef]

12. Aceto, M.; Abollino, O.; Bruzzoniti, M.C.; Mentasti, E.; Sarzanini, C.; Malandrino, M. Determination of metals in wine with atomic spectroscopy (flame-AAS, GF-AAS and ICP-AES); a review. Food Addit. Contam. 2002, 19, 126-133. [CrossRef] 
13. Manousi, N.; Gomez-Gomez, B.; Madrid, Y.; Deliyanni, E.A.; Zachariadis, G.A. Determination of rare earth elements by inductively coupled plasma-mass spectrometry after dispersive solid phase extraction with novel oxidized graphene oxide and optimization with response surface methodology and central composite design. Microchem. J. 2020, 152, 104428. [CrossRef]

14. Kazantzi, V.; Drosaki, E.; Skok, A.; Vishnikin, A.B.; Anthemidis, A. Evaluation of polypropylene and polyethylene as sorbent packing materials in on-line preconcentration columns for trace $\mathrm{Pb}$ (II) and $\mathrm{Cd}(\mathrm{II})$ determination by FAAS. Microchem. J. 2019, 148, 514-520. [CrossRef]

15. Ma, X.; Huang, B.; Cheng, M. Analysis of trace mercury in water by solid phase extraction using dithizone modified nanometer titanium dioxide and cold vapor atomic absorption spectrometry. Rare Metals 2007, 26, 541-546. [CrossRef]

16. Viñas, P.; Pardo-Martínez, M.; López-García, I.; Hernández-Córdoba, M. Determination of mercury in baby food and seafood samples using electrothermal atomic absorption spectrometry and slurry atomization. J. Anal. At. Spectrom. 2001, 16, 633-637. [CrossRef]

17. Gopalani, M.; Shahare, M.; Ramteke, D.S.; Wate, S.R. Heavy Metal Content of Potato Chips and Biscuits from Nagpur City, India. Bull. Environ. Contam. Toxicol. 2007, 79, 384-387. [CrossRef] [PubMed]

18. Christodoulou, E.A.; Samanidou, V.F. Multiresidue HPLC analysis of ten quinolones in milk after solid phase extraction: Validation according to the European Union Decision 2002/657/EC. J. Sep. Sci. 2007, 30, 2421-2429. [CrossRef] [PubMed]

19. Papadoyannis, I.N.; Samanidou, V.F. Validation of HPLC Instrumentation. J. Liq. Chrom. Relat. Tech. 2004, 27, 753-783. [CrossRef]

20. IUPAC. Compendium in Chemical Terminology, Version 2014; Blackwell Scientific Publications: Oxford, UK, 1997.

21. Narin, I.; Tuzen, M.; Sari, H.; Soylak, M. Heavy metal content of potato and corn chips from Turkey. Bull. Environ. Contam. Toxicol. 2005, 74, 1072-1077. [CrossRef] [PubMed]

Publisher's Note: MDPI stays neutral with regard to jurisdictional claims in published maps and institutional affiliations.

(C) 2020 by the authors. Licensee MDPI, Basel, Switzerland. This article is an open access article distributed under the terms and conditions of the Creative Commons Attribution (CC BY) license (http://creativecommons.org/licenses/by/4.0/). 